\title{
The W-model: a pre-college design pedagogy for solving wicked problems
}

\author{
Christopher Moraes $^{1}$ (D) . Stefanie Blain-Moraes ${ }^{2}$ (D) . Sierra Morell-Tomassoni ${ }^{3}$. \\ Robert B. Gorbet ${ }^{4}$
}

Accepted: 3 August 2019

(c) Springer Nature B.V. 2019

\begin{abstract}
Many design frameworks introduced to novices are not compatible with the behaviours and habits of mind of expert designers. This creates a barrier to effective practice, especially when novice designers tackle ill-defined, wicked problems. The $\mathrm{W}$-model is a pedagogical framework that provides a prescriptive design model for novices, enabling them to effectively engage with ill-defined problems. Co-evolution of the problem and solution are mandated through rapid iterations of five design phases: define, ideate, synthesize, assess and reflect. The $\mathrm{W}$-model was tested on pre-college novice designers who used this framework to solve a wicked problem. Results demonstrate that students using the $\mathrm{W}$-model engaged in behaviours associated with informed designers, and were able to effectively and confidently tackle a real-world problem.
\end{abstract}

Keywords Design framework · Wicked problems · Novice designers · Design pedagogy

\section{Background}

The past decade has seen an increasing push for design education to be introduced at the pre-college level (International Technology Education Association 2002; Mcadoo 1998; National Research Council 2005). At the same time, multiple professions are increasingly involved in addressing complex and wicked problems in society (Adams et al. 2003; Dym et al. 2005; Jonassen 2000; Jonassen et al. 2006; Lucky 2009; Wodehouse et al. 2010). It is important, therefore, that students being taught design are presented with a pedagogy that is compatible with the habits and practices used to address wicked problems, while being

Christopher Moraes and Stefanie Blain-Moraes contributed equally to this work.

Stefanie Blain-Moraes

stefanie.blain-moraes@mcgill.ca

1 Department of Chemical Engineering, McGill University, Montreal, QC, Canada

2 School of Physical and Occupational Therapy, McGill University, 3654 Prom Sir William Osler, Montreal, QC H4X 1N3, Canada

3 Department of Industrial Engineering, University of Michigan, Ann Arbor, USA

4 Department of Knowledge Integration, University of Waterloo, Waterloo, ON, Canada 
appropriate for their grade and experience level. This places a burden on K-12 educators who, for the most part, have no personal experience with the practice of design, or design education. In this paper, we present and assess the W-model: a novel pedagogy for teaching pre-college design that is compatible with wicked problems and supports novice designers' progression towards more informed design practice.

\section{The importance of addressing wicked problems in pre-college education}

The complex needs of modern society demand innovative and creative engineers, able to address globally significant problems and challenges. Individuals from a multiplicity of educational backgrounds are now included on teams that tackle large-scale, global problems such as improving the quality of life of children with disabilities, supporting the aging population, or managing limited and dwindling natural resources. These complex problems are often poorly-defined (Simon 1969), and termed "wicked": a system of interdependent problems in which stakeholders do not share the same value assumptions or ideological considerations (Dunne and Martin 2006; King 1993; Rittell and Webber 1972, p. 22). It has become increasingly important for students to develop the skill set necessary to tackle problems of this nature. In response, education must evolve to include design pedagogy that teaches students to grapple with wicked problems and to generate successful solutions to them.

Effective design pedagogy accounts for typical trajectories that students follow when learning design, and sets learning goals that can help students acquire competency in a timely fashion. While teachers who are expert designers can draw upon experience to guide students away from their beginner tendencies towards more effective design habits, those who do not have design experience or the knowledge to teach effectively with design challenges (Hynes 2012) may inadvertently reinforce students' design misconceptions, ineffective design behaviours, and inefficient habits of mind. For example, teaching design simply as a series of steps to be traversed may inadvertently teach students that design is a linear, non-iterative process. This is especially a concern in the pre-college setting, where design is becoming more integrated into the curriculum. For example, the Committee on K-12 Engineering Education recommends that learning engineering design become a key feature of K-12 engineering education (Katehi et al. 2009), and other professional and educational groups continue to push for its inclusion in the pre-college classroom (International Technology Education Association 2002; Mcadoo 1998; National Research Council 2005). Consequently, many students' first exposure to design will occur with a teacher who has little to no personal design experience and little training in guiding the design process. Providing these teachers with an accessible and effective pedagogical model for teaching engineering design is critical to ensuring a strong design foundation and a positive learning experience for the student (Hynes 2012). The field of design is replete with hundreds of prescriptive and descriptive design process models (Andrews and Goodson 1980; Dubberly 2005), and educators have traditionally begun with simple design pedagogical models, assuming that the process of learning to solve well-structured problems translates well to solving ill-structured and wicked problems. However, recent research has demonstrated that learning to 'solve' problems does not readily transfer to an ability to define and scope problems, which is a crucial step in addressing ill-structured problems (Cho and Jonassen 2002; Schraw et al. 1995; Shin et al. 2003). Problem scoping and problem solving require different cognitive processes (Jonassen 2000). Indeed, introducing design using a simple model may make students less ready to deal with the ambiguities of ill-defined problems 
(Adams et al. 2003; Crismond et al. 2001; Daly et al. 2012; Lande and Leifer 2010). Presenting a design pedagogical model that is able to address wicked problems is crucial both to addressing these issues, and to empowering and attracting students towards fields of study which will allow them to address global challenges (Tai et al. 2006).

\section{Goal of pre-college design education: producing an "informed designer"}

Creating effective design pedagogy involves identifying appropriate starting points and realistic end goals for student design performance. In the design model presented in this paper, we consider our pedagogical trajectory with respect to a three-stage model of developing design expertise that includes naïve, novice and expert levels of performance (Crismond 2001). Our model is targeted towards the behavior and thinking of the beginner designer-a student with little to no experience and no formal training in design. The goal is to produce an "informed designer", whose level of competence in design is somewhere between that of the novice and expert designer. The informed designer has been referred to as an "advanced novice" (Dreyfus and Dreyfus 2005), "expertlike novice" (Bereiter and Scardamalia 1993), "expert student" (Sternberg 1998) and "competent performer" (Dreyfus et al. 1986) in other contexts.

\section{Evaluating design pedagogies using the informed design teaching and learning matrix (IDTLM)}

In order to evaluate the effectiveness of different pre-college design pedagogies, we turn to the Informed Design Teaching and Learning Matrix (IDTLM) developed by Crismond and Adams (2012). The IDTLM is a robust framework for a scholarship of design teaching and learning relevant to K-16 engineering contexts. It presents nine engineering performance dimensions that are central to informed design. Within each of these dimensions, it identifies design strategies and patterns associated with beginner design behavior, and those associated with informed design behavior (Table 1). The ideal design pedagogy would include elements targeting each design strategy, avoiding behaviours associated with beginner designers and encouraging those associated with informed designers.

\section{Existing pre-college design pedagogical frameworks}

Over the past decade, several models for teaching design to pre-college students have been developed to teach students to transition from beginner to informed designers. Here, we review four current, broadly-used design models for pre-college students and illustrate their strengths and weaknesses as they apply to addressing wicked problems.

1. Project Lead the Way (PLTW) provides STEM education curricular programs to over 400,000 middle and high school students in schools in all 50 states of the United States ("Project Lead The Way"). Their 12-step design process is taught to 9th or 10th grade students in the Introduction to Engineering Design course (Fig. 1a).

2. Design Squad is a PBS reality television show where middle and high school student compete in design challenges to win a college scholarship. The design process they developed for parents and educators of these students is depicted in Fig. 1b (Design Squad Nation). 


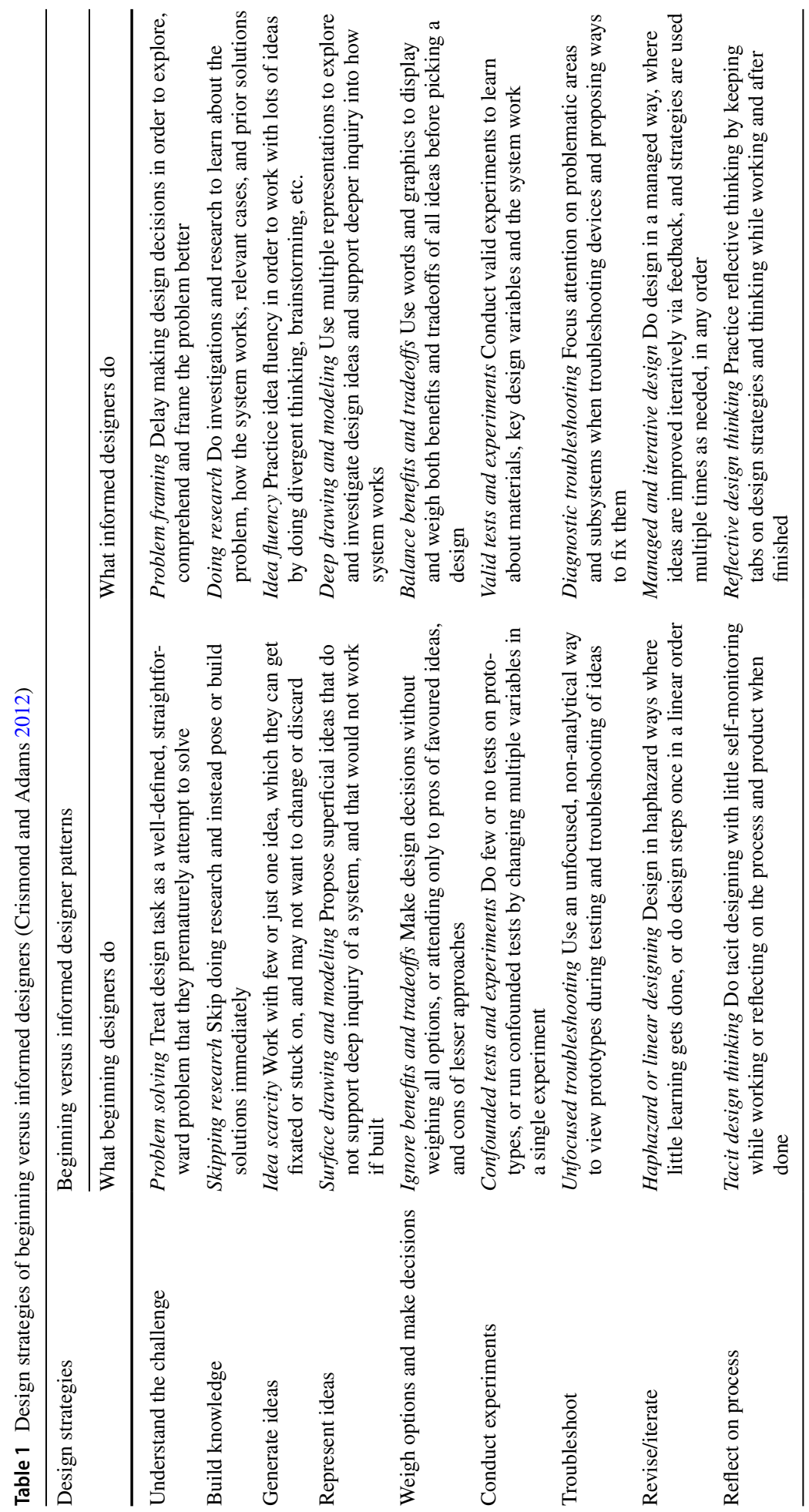



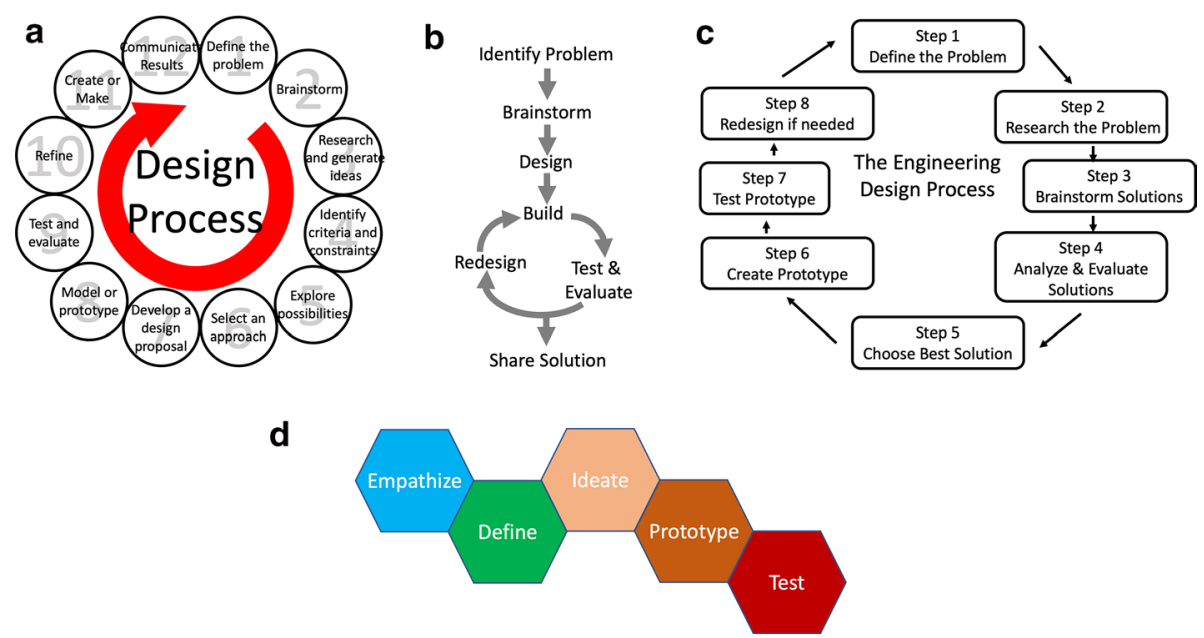

Fig. 1 Popular pre-college design pedagogical frameworks developed by a Project Lead the Way (PLTW), b Design Squad, c Applied Design Engineering Project Teams at the University of California, Berkeley, d the K12 Lab in the Stanford Institute of Design. Figure panels adapted from references ("Project Lead The Way"; Design Squad Nation; Mangold and Robinson 2013; K12 Lab Network)

3. Applied Design Engineering Project Teams (ADEPT) at the University of California at Berkeley develop and deploy engineering curriculum for middle and high school students (Mangold and Robinson 2013). Figure 1c illustrates the design process these teams use to teach students to tackle 'hands-on—minds-on' engineering projects.

4. The Stanford Institute of Design (d.school), created by David Kelley, founder of design company IDEO, developed a K-12 laboratory ("K12 Lab Network") to teach design thinking to pre-college students. One version of the design process taught by this lab is illustrated in Fig. 1d.

\section{Review of existing frameworks using IDTLM}

We briefly review the utility of these existing design pedagogical frameworks in the context of wicked problems according to the design strategies presented in the IDTLM.

\section{Understand the challenge}

The first step in the design models presented in Fig. 1a-c is "define/identify" the problem. While this step is relatively straightforward for problems that are clearly stated (e.g., a design brief, or request for proposal), wicked problems do not have a definite formulation (Rittell and Webber 1972) and thus do not provide this starting point. Wicked problems are ill-structured, have multiple and often conflicting goals, and ambiguous definitions of success (Jonassen et al. 2006), making it nearly impossible to define the problem to be solved during a first attempt at the beginning of the design process. The design model in Fig. 1d addresses this with an "empathize" step before defining the problem; however, the process of empathizing with all of the facets of a wicked problem is staggering and often requires years of immersion in the problem. Furthermore, activities to teach empathy that 
are available within the resources of typical K-12 classrooms can often provide false and misleading information and cultivate stereotypes towards the target user group. For example, simulation exercises are extensively used to understand people with disabilities, but these exercises often fail to simulate impairment correctly, and often instills negative rather than positive attitudes towards this target group (French 1992); designers who begin developing solutions from such a premise will likely not arrive at a successful solution.

Understanding the challenge of a wicked problem requires, in large part, identifying the right frame for the problem to be solved. Informed designers continuously co-construct understandings of problems and possible solutions (Maher and Tang 2003) and attempt to understand more about the wicked problem in the process of developing potential solutions (Beckman and Barry 2012). These problem-solution coevolution strategies are critical in dealing with more complex systems, and characteristic of the creative approaches required in such situations (Dorst and Cross 2001). This approach of continuously defining and redefining the problem requires a rapid cycling between abstract problems and concrete solutions, using the current framing of the problem to create better solutions, and assessing the solutions to develop a better understanding of the problem (Beckman and Barry 2012; Hatchuel et al. 2011; Hatchuel and Weil 2003). An effective design pedagogical model for wicked problems should incorporate such problem-solution co-evolution, forcing designers to continuously refine their understanding of the challenge throughout the design process (Archer 1979; Lawson and Dorst 2009). None of the currently used design frameworks presented in Fig. 1 specifically addresses this issue.

\section{Build knowledge}

Research is not explicitly included in the design models presented in Fig. 1b or d, and included as the second or third step of the process in Fig. 1a, c. These models are similar to a 'waterfall model', which encourages students to spend time learning about and analyzing the problem before developing and implementing a selected solution (solid line in Fig. 2).

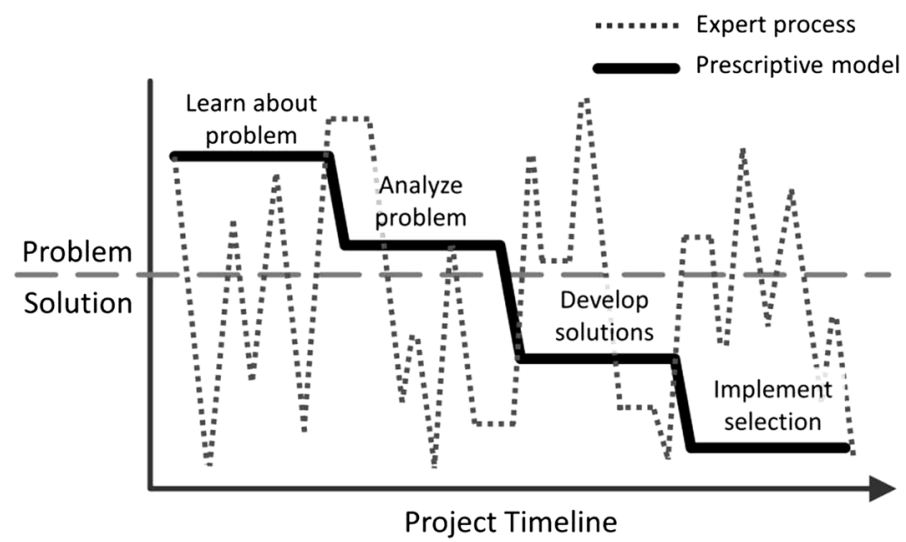

Fig. 2 A comparison of expert design behaviour and commonly taught prescriptive frameworks. Typical prescriptive pedagogical frameworks encourage students to spend time learning about and analyzing the problem, before developing and implementing a selected solution. In contrast, experts when presented with a problem tend to leap to a solution, and engage in multiple iterations to simultaneously coevolve their understanding of the problem and potential solutions. Adapted from Conklin and Weil (2007), based on data produced by Guindon (1990) 
However, studies have demonstrated that successful designers seek less information to begin with than less successful designers (Christiaans and Dorst 1992), and that the work of building knowledge is rarely done in one burst at the beginning of the design process (Schön 1988). Informed and expert designers follow a process typified as the dotted line in Fig. 2, where building knowledge through learning about and analyzing the problem happens continuously throughout the design process. An effective design pedagogical model for wicked problems should encourage research throughout the design process, as understanding of the problem evolves. It is important to note that building knowledge to better understand the problem can be extended beyond the process of doing research. Conducting experiments and prototyping are also effective ways of building knowledge, provided that the results of the experimentation and prototyping are reflected into an improved understanding of the overall problem.

\section{Generate ideas; represent ideas; weigh options and make decisions; conduct experiments; troubleshoot}

Each of the design models presented in Fig. 1 include components that address each of these design strategies. The behaviours of informed designers (see Table 1) in each of these design stages are similar across wicked and well-structured problems.

\section{Revise/iterate}

The design models in Fig. 1a-c explicitly indicate an iterative process at the end of the design process "if needed" (Fig. 1a, c), or only within the process of building the solution (Fig. 1b). The model in Fig. 1d supports but does not prescribe iteration. These models do not capture the essential nature of iteration to the process of solving a wicked problem. When students are told to iterate once a product has been built, this often leads to simple refinement of the solution (e.g. "Maybe the prototype should be blue"). However, iteration in designing solutions to wicked problems must engage meaningful learning, where new insights and information gleaned from assessing solutions are continually assimilated into a designer's understanding of the problem (Adams et al. 2003; Schön 1983). Designers must continually evolve their understanding of the problem at hand, and informed designers will combine problem structuring and solving in an iterative process (Adams et al. 2003; Jr and Gyeszly 1991; Lawson and Dorst 2009). A design pedagogical model that is effective for wicked problems will structure multiple iterations throughout the design process, and support continual iteration of both understanding of the problem and design of the solution.

\section{Reflect on process}

Reflection is not included in any of the existing design models highlighted in Fig. 1. However, reflection and metacognition can provide valuable feedback that improves both design process and product. Reflective process in design is associated with higher levels of design performance and product quality (Adams and Atman 2000). This process enables designers to revisit assumptions when faced with evidence that their assumptions have become problematic (Perkins 1995, pp. 218-220), and to pay attention to the progress they make and the design values that influence their decisions.

In summary, the popular pre-college design pedagogies surveyed do not effectively address four of the IDTLM design strategies in the context of wicked problems: understand 
the challenge, build knowledge, revise/iterate and reflect on process. These strategies are primarily related to 'conceptual design' (i.e., answering "what is it I want to accomplish?") as opposed to 'detail design' (i.e., answering “how will I accomplish it?”). While conceptual design is present to some degree in all design problems, understanding and navigating this process is especially important in developing successful solutions for wicked problems.

\section{Presentation of the W-model}

\section{Overview of the W-model}

The W-model is a framework for pre-college students that teaches and supports strategies that informed designers use to address wicked problems. It primarily addresses strategies of informed conceptual design, as well as supporting general behaviours associated with informed designers.

The overall design process described in our framework is graphically depicted in Fig. 3a. Broadly, designers follow a series of iterative cycles beginning with a wicked problem, and

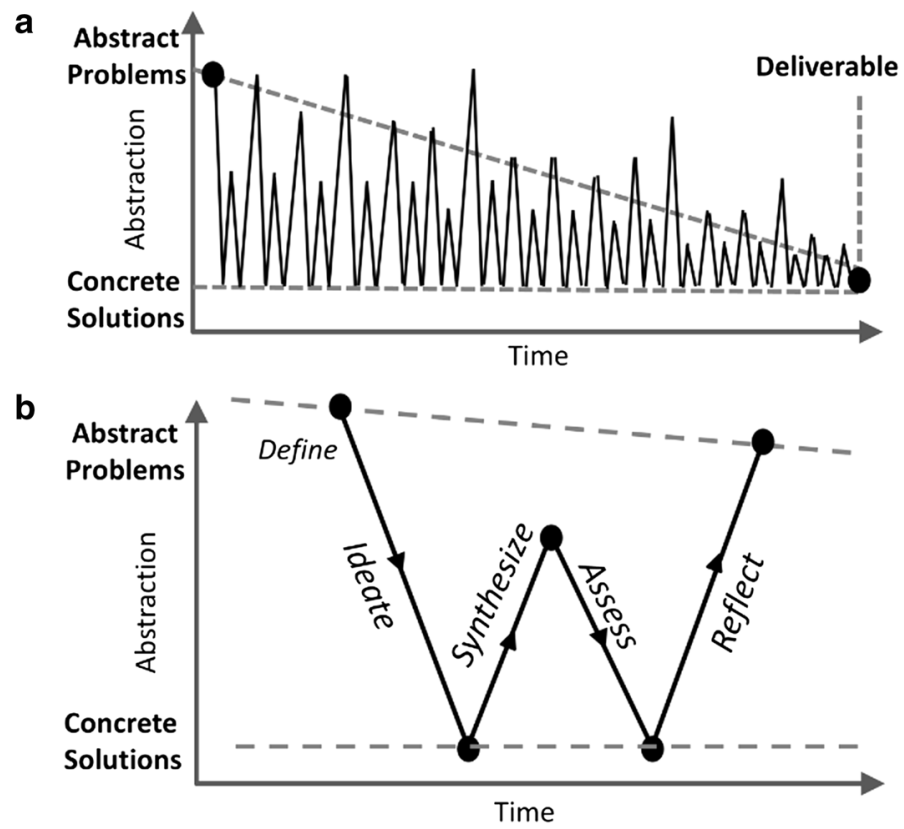

Fig. 3 The W-model design process. a Students are expected to engage in multiple iterations of a 'messy' design process, in which they rapidly switch between defining extremely abstract problems and developing very concrete solutions. When presented with a problem, students are expected to solve it immediately, and then apply the knowledge developed in the process towards better understanding the question. Progress from a wicked problem to a deliverable is not expected to be linear, but an understanding that time and resources are finite is used to ensure that students produce a deliverable. b Within an individual 'W' cycle, students progress through five phases. First, they define an abstract question, and then jump into ideating multiple solutions. Solutions are then clustered and synthesized into themes, based on identifying why each solution might work in solving the problem. These themes are then assessed based on prescribed generalized criteria, and students use built-in reflection time to refine their understanding of the question 
eventually converging on a deliverable at the end of the process. In proceeding towards the deliverable, designers engage in thinking at different levels of abstraction: while problems are considered as more abstract questions, solutions can be thought of as being concrete answers. Over time, as designers gather more information regarding the technical and social aspects of the problem, their process becomes less abstract, until it converges with a concrete solution, resulting in a deliverable that addresses the wicked problem.

A single iteration of our prescribed design cycle is graphically depicted in Fig. 3b. The designers begin the cycle by defining their current understanding of the problem. In the first iteration this definition is the wicked problem itself. In subsequent iterations, the problem definition is based on the designers' refined understanding of the problem. They then immediately ideate and collect multiple, concrete solutions to the problem, using creative idea generation techniques. These possible solutions are then synthesized and generalized based on why the solution might address the problem, in order to identify any underlying themes. These themes are then assessed according to specific criteria, and the designers then reflect upon their findings to generate a more informed understanding of the overall problem. The insights gained during this sequence of phases should increase the designer's awareness of the social and/or technical considerations of the problem, bring to light implicit assumptions about the problem or solution, and may introduce additional problemsolving criteria or constraints. This sets the starting point for a subsequent design cycle. The goal of each cycle is to gain a better understanding of the problem, and thus, to narrow the scope of the problem being addressed in the subsequent cycle. A problem that is broadly scoped in an early design cycle (e.g., "How might we address global poverty?") becomes more tightly scoped as designers progress through subsequent cycles (e.g., "How might we equalize earnings between urban and rural settings", to "How might we transport items between City X and Farm Y?").

\section{Review of W-model using IDTLM}

The W-model shares common characteristics with many existing models for design, including those represented in Fig. 1. However, our framework uniquely addresses the following design strategies from the IDTLM in a manner that makes it amenable to solving wicked problems.

\section{Understanding the challenge}

One of the biggest challenges in addressing wicked problems is that they involve elements and parameters that are only partially determined at the beginning of the design challenge (Buchanan 1992; Rittell and Webber 1972). Compounding this challenge, students (and often experts) do not necessarily know the important questions that need to be asked in order to gain a better understanding of a problem, nor do they understand how to identify unknown elements and parameters. As a result, the first approach for many students is to enter the wicked problem into an online search engine, a practice that has been demonstrated to significantly bias and reduce diversity in the information with which students shape their understanding of the problem (Goldman 2006). Anecdotally, we have also noticed that repeated emphasis placed on thoroughly understanding the problem before attempting to solve it, often leads to paralysis in normally high-performing students: they fear making a decision and moving forward, in case the selected solution is a poor one. 
Informed designers will "delay making design decisions in order to explore, comprehend and frame the problem better" (Crismond and Adams 2012). This behavior is counter to the beginner tendency to immediately devise plans to solve the problem (Christiaans and Dorst 1992, p. 132), making "premature commitments" (Cross 2008) to initial solutions. Some expert designers are able to employ knowledge development strategies to gain a better understanding of the problem while meticulously avoiding making any early design decisions. It is unlikely, however, that beginner designers will have command of such strategies of practice. Other experts explore a problem by rapidly generating interim solutions that are used to better inform their understanding of the problem (Maher and Tang 2003). The W-model follows the strategy of these latter experts, and suggests that students first define their current understanding of the problem, and then immediately and fearlessly jump to generating multiple, concrete solutions, given whatever understanding, experience, and intuition they might already have. We emphasize that the initial solutions they generate will likely not solve the wicked problem, but that this is simply the first step in getting a better understanding of the underlying issues. The subsequent steps of synthesis, assessment and reflection are explicitly designed to extract salient features from the pool of solutions, which then furthers their understanding of a problem.

To emphasize the importance of continually developing and refining a student's understanding of the problem, the W-model describes the outcome of each design cycle as an improved understanding of the problem. The end of one design cycle converges with the beginning of the subsequent cycle in the "define" phase, wherein students identify what they have learnt from previous design cycles and incorporate this knowledge into a better understanding of their wicked problem. This approach of continuously refining the problem through a rapid cycling between abstract problems and concrete solutions is consistent with the behavior of expert designers tackling a wicked problem (Beckman and Barry 2012; Hatchuel et al. 2011; Hatchuel and Weil 2003).

\section{Generating ideas}

While beginner designers work with few or just one idea, which they can get fixated or stuck on, informed designers practice idea fluency in order to work with lots of ideas (Crismond and Adams 2012). In the "ideate" phase of the W-model, students are encouraged to use idea generation techniques, including brainstorming (Osborn 1963), research, sketching and prototyping, in order to generate as many ideas as possible by actively building on each other's ideas, driving for 'wild and crazy' solutions, and consciously withholding judgment and criticism on any aspect of them until after the session is complete. In theory, this continuous positive feedback encourages everyone to be as creative as possible. However, while this approach is attractive in its simplicity, nearly a decade of research has demonstrated that brainstorming in isolation of other activities is simply not effective in improving the number and diversity of ideas generated by a group (Byron 2012; Kohn and Smith 2011; Nemeth et al. 2003). While psychological effects such as collaborative fixation (Kohn and Smith 2011) might be addressed by encouraging students to generate ideas independently before engaging with a group, there are two greater concerns with this process. First, the rules of brainstorming expressly forbid criticism during the process, while researchers have shown that intervals of criticism significantly boost translatable creative idea generation (Nemeth et al. 2003). Training young students in particular to effectively switch between creative and critical modes of thinking is challenging. Second, although 'wild and crazy' ideas are supposedly generated to improve creativity, we have often 
observed that these are merely used as a vehicle for humour, and then promptly ignored as being impractical or unfeasible. When this occurs, 'crazy ideas' serve no purpose except to increase the number of ideas generated by the group, without providing any tools or insights that may be useful in the design process.

We address these potential limitations of the "ideate" phase and encourage students to practice idea fluency by introducing the subsequent "synthesis" and "assess" phases in the W-model. In the "synthesis" phase, students are asked to identify the underlying conceptual and abstract themes of each of the proposed solutions. Students are asked to cluster solutions into groups with similar qualities, and identify underlying abstractions that might help solve the problem. This synthesis phase forces participants to extract useful information from the generated ideas, including the 'wild and crazy' ones. In the "assess" phase, students engage in constructive conflict and criticism around these solutions and abstractions, informed by research, prototyping, testing and interviewing users. By encouraging participants to understand why a solution might work, and abstracting a kernel of interesting information from the crazy idea, they should be able to arrive at new and interesting ways of looking at a problem. This also results in students effectively utilizing all ideas from a brainstorm, including those that seem completely impractical and unfeasible. Rapid iteration through the design cycles of the $\mathrm{W}$-model results in introducing intervals of criticism between intervals of free-wheeling creativity, which we predict will improve idea fluency (Nemeth et al. 2003).

For example, consider the wicked problem, "How might we improve student learning in North American elementary schools?" The design team ideates several "solutions" (which may or may not be good ones), amongst which are: (1) cancel school in favor of circus visits; (2) make students into teachers for a day; (3) engage interesting guest speakers; (4) no more detentions; and (5) dunk tank for wrong answers. Based on synthesizing themes from these samples, designers might identify interesting aspects of the problem, such as "Improving interest in subject matter" (from 1, 2, 3), or "Experiential learning" (from 1, 3), or "Get rid of teachers altogether" (from 1, 2, 3), or "Motivational punishment" (from 2, 4, 5 ), or "Leveraging rebellious behavior" (from 1, 4, 5). These broad categories then provide a basis with which to conduct a thorough assessment: designers are expected to engage in unfiltered debate, once again using secondary research, primary surveys of stakeholders, prototyping, etc. to establish the merits of each theme. After reflecting on these findings, the design team can elect to define the next cycle based on a better-defined question. In this example, their research may lead them to retain "Improving students' interest in the subject matter" and "Leveraging rebellious behavior" for further consideration, resulting in the refined questions: "How might we improve students' connection to the subject matter in North American elementary schools?" or "How might we align learning opportunities with rebellious attitudes in North American elementary schools?"

\section{Weighing options and making decisions}

Informed designers "use words and graphics to display and weigh both benefits and tradeoffs of all ideas before picking a design" (Table 1). In the W-model, synthesized themes are measured in the 'assess' phase against three criteria: desirability, feasibility and viability (Brown 2009). Desirability is what makes sense to people and for people. It includes concepts such as validity, which is the potential of a design along a proposed theme to address an overall wicked problem. Novice designers are taught to ask the question, "If we design a solution around this theme, will we make a significant difference to the wicked problem?" 
Desirability also includes measures of internal motivation, or the interest and excitement that a design team has for a particular problem or solution. Feasibility accounts for what is functionally possible within the foreseeable future. Feasibility includes technical potential, which tests whether solutions can be implemented in practice, given the current state of knowledge and technology. Designers ask, "Is it possible for someone to build this?" Feasibility also includes the capabilities of the design team, including time, budget, skill set, and available resources (or, "Is it possible for us to build this?"). Viability describes whether this approach could become part of a sustainable business model. To simplify assessment of this component, we suggest that students evaluate marketability, or the likelihood of this solution being appealing to consumers.

\section{Building knowledge}

Informed designers "do investigations and research to learn about the problem, how the system works, relevant cases, and prior solutions". The process of determining the desirability, feasibility and viability of themes during the 'assess' phase of the W-model naturally lends itself to building knowledge. For example: determining desirability of themes may involve conducting user surveys or focus groups; assessing feasibility may involve building and testing a prototype; and assessing viability may involve researching prior solutions. (It is worthwhile to note that while the ubiquitous design tools of research and prototyping are most often employed in the 'assess' phase, we also encouraged students to also use them in the 'ideate' phase as tools for seeding ideas and encouraging idea fluency.)

\section{Reflecting on process}

Wicked problems do not have implicit stopping criteria, because of their interconnected nature and the difficulty of imposing "true-or-false" measures on problems that include social considerations (Rittell and Webber 1972). With a little more time, a little more effort, a designer might always find a better solution. In practice, however, designers must work within limited resource budgets, and the need to produce a deliverable necessitates moving towards concrete solutions. Because of this reality, we emphasize that the purpose of the design process is to move ultimately towards a deliverable. To aid in this, we have defined explicit stopping criteria for the design process. The process terminates under one of two conditions: (1) a deliverable is produced that satisfies both the designer and the criteria of the problem (extremely unlikely given the constraints in a pre-college education setting), or (2) the limited resources with which to address the problem (e.g., time, money) force the designer to stop the process and produce a deliverable based on the social and technical understanding acquired at that point. In the 'reflect' phase of the W-model, not only are designers reflecting upon what they have learnt in the previous design cycle, they are also encouraged to reflect on where they are in the overall design process, and how to modify their design strategies according to how close they are to the defined stopping criteria. Informed designers "practice reflective thinking by keeping tabs on design strategies and thinking while working and after finished" (Crismond and Adams 2012). 


\section{Iterating}

The W-model encourages iterating through many design cycles before coming to a final solution to a wicked problem. While the design process does have the overall convergent trend shown in Fig. 4a, it is important to acknowledge that linear convergence in each cycle is not realistic, or even desirable. Although our 'idealized' design cycle represented in Fig. 4b suggests constantly decreasing levels of abstraction from a wicked problem towards a concrete solution, the reality admits several possibilities. A design cycle which "narrows scope" results in an improved understanding of the problem (Fig. 4a). However, a design cycle may also result in an "unchanged scope": questions may be asked in a design cycle, ideas generated, concepts synthesized, and assessment completed, and we may not be able to say anything more concrete about the problem (Fig. 4b). Alternatively, something new about the problem may be discovered that invalidates the current problem, and designers need to "broaden scope" (Fig. 4c). We emphasize for students that every design cycle brings new information and informs our understanding of the problem, and that even so-called broadening-scope design cycles are a valuable and normal part of the design process. It is in the process of multiple iterations that the scope of the problem eventually becomes narrow enough to produce a solution.

For example, consider the problem of designing an infrastructure-free portable toilet. The design may have progressed through several iterations towards a more specific and concrete understanding of the problem, when it is discovered in one design cycle that criteria such as environmental impact are of great importance, and had not been previously considered. The current understanding of the problem is hence invalidated. In this example we still learn more about the problem, but the result of the design cycle is that we need to back up one or more cycles, beginning again at an earlier cycle with a more broadly scoped problem.

\section{Predicted outcomes of using the W-model}

Based on the review of the W-model using the IDTLM, we predict the following behavioral outcomes of pre-college students using the W-model to address a wicked problem, and the evidence of this outcome in design practice (Table 2).
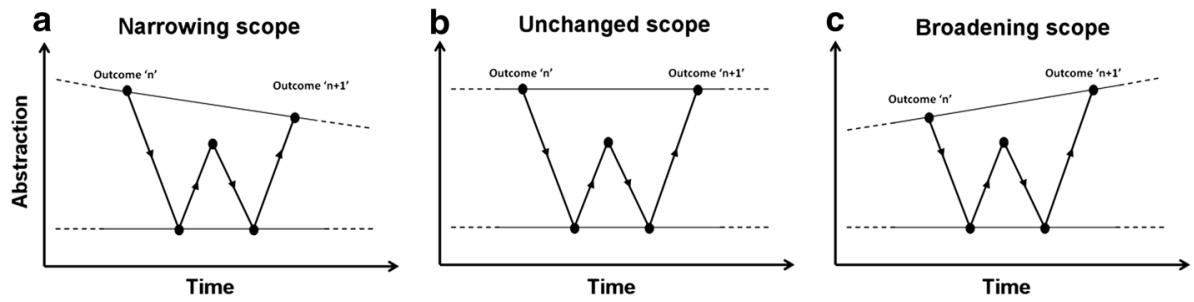

Fig. 4 Expected results of each W-cycle. Going through a cycle may result in a narrowed scope, in which the problem posed becomes less abstract; $\mathbf{b}$ an unchanged scope, in which the design cycle does not better inform the designer; or c a broadened scope, in which designers realize that the problem they are working on no longer addresses the wicked problem. Students are taught that each of these outcomes produces important information, and that solving a wicked problem requires designers to make 'mistakes' that better inform the coevolution of problem and solution 


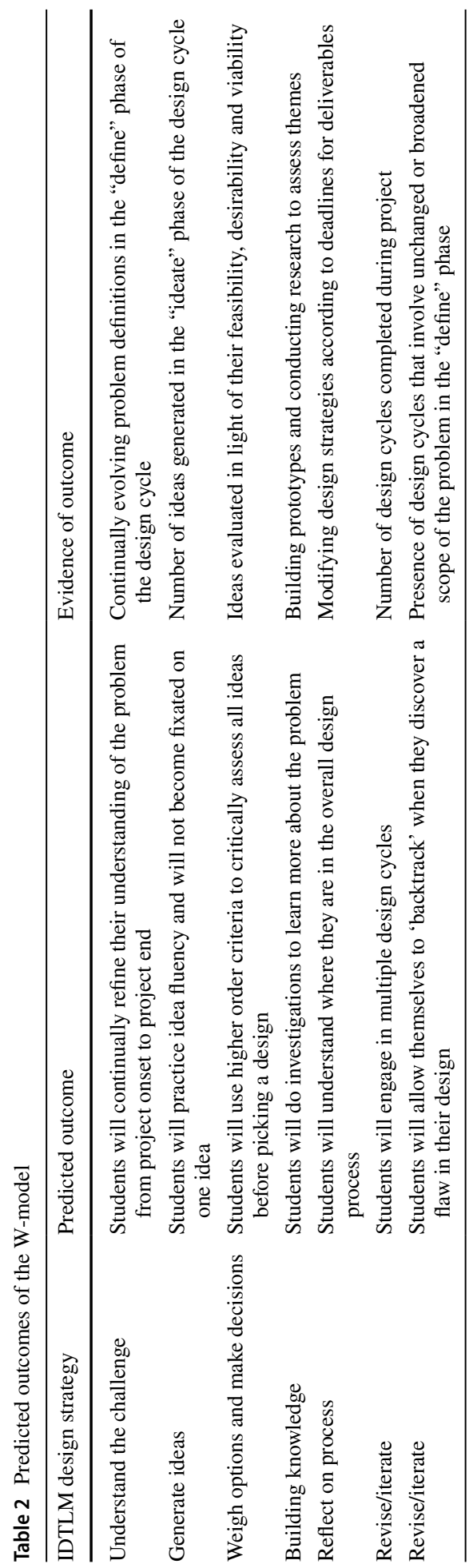




\section{Mixed-methods study of the W-model}

\section{Study background}

\section{Study design}

In order to study the design behaviours of pre-college students who use the $\mathrm{W}$-model to address a wicked problem, we conducted a mixed-methods study using a convergent triangulation design (Creswell et al. 2010). In this design, qualitative and quantitative data are gathered concurrently to obtain different but complementary data on the same topic, and data are converged during the interpretation to best understand the research problem (Morse 1991). We were committed to a pragmatic epistemological approach (Morgan 2007) and an outsider positionality with respect to the design students.

\section{Teaching environment}

Shad Valley (http://www.shad.ca) is an award-winning Canadian summer enrichment program in which groups of gifted high school students spend 4 weeks living in residence at a university campus, immersed in an undergraduate-level learning experience and community. At each of the host campuses, students are exposed to advanced topics in design, science, engineering, mathematics, and business, amongst others. They also undertake a design project to address a wicked problem (Carson et al. 2008). In previous years, these have included such problems as, "How might we solve the Canadian energy crisis?", "How might we improve the quality of life of children with disabilities?", and "How might we improve crime prevention across Canada?"

\section{Participants}

All of the students $(n=48 ; 28$ female, age 16.5 \pm 0.7 years $)$ attending Shad Valley Waterloo participated in the study. Participants formed 9 design teams consisting of between 4 and 6 individuals. During the project, teams were randomly assigned a colour identifier, which was used to keep track of notes, progress and discussion. For purposes of anonymity in this publication, teams have been listed based on arbitrary assignment to a letter of the alphabet. Ethics approval was received for this study from the University of Waterloo.

\section{Design project}

During the first week of the program, program staff conducted approximately $15 \mathrm{~h}$ of in-class design lectures and exercises, including several examples of real-world designers solving problems, the concepts behind the W-model, detailed methods and best practices in each of the phases, and related lectures including prototype development and team design skills. Approximately $30 \mathrm{~h}$ of time was then scheduled for students to work on their design project over the next 2 weeks of the program. Staff was available for consultation and mentorship during each of these project sessions, but generally not assigned to follow or supervise specific students. Students were also free to use unscheduled time to work on their projects. 
The design project focused on the wicked problem, "How might we reduce/prevent obesity in North American youth?" Students were asked to develop a simple business plan around their solution. The project topic was revealed after the in-class instruction segment, and several interim deliverables were established to ensure that students remained on track. For analysis purposes, the project was divided into four quarters based on the length of time assigned for the design project, and on the deliverable timelines. Final project deliverables consisted of a prototype, a company website, a conference-style poster to explain their product or service, and a logbook detailing their activities during the project. Interim deliverables included brief presentations of current problem statements and current prototypes, at the end of the project quarters.

None of the work is graded, but feedback is provided on each deliverable and on request at any time in the process, to help students set their own learning expectations and improve their own work.

\section{Methods}

The design process of each team was documented using retroactive analysis of team logbooks, where teams recorded their daily design activities and their progress through the design cycle. Students were expected to maintain this logbook for both scheduled and unscheduled project time. While there were no specific prompts that students were required to fill out, they were encouraged to include all notes, sketches, pictures and charts that summarized their design activities. Groups submitted their logbooks to staff members on several occasions for feedback on their record keeping, and to ensure they were recording their design activities in a thorough and accurate manner. To validate the accuracy of the student records, staff members were present during design group meetings, where they independently tracked the phases of the design process executed each day. Upon completion of the design project, qualitative data were collected using a semi-structured questionnaire, which was administered to all 48 participants. The semi-structured, self-report instrument was developed to test the eight predicted behavioral outcomes of the W-model presented in Table 2.

\section{Analysis}

\section{Logbooks}

Logbooks for each of the teams were coded for the phases in the W-cycle: define, ideate, synthesize, assess and reflect. To validate the accuracy of student-recorded information in the logbooks, observations made by staff observers during project meetings were similarly coded, and paired with data collected from the logbooks. The strength of correlation between data obtained from the two observations was tested using Cohen's Kappa analysis (Cohen 1960).

Subsequently, coded data from the logbooks were used to test each of the predicted outcomes of the W-model according to the "evidence of outcome" listed in Table 2. A one-way analysis of variance (ANOVA) followed by a post hoc Student-Newman-Keuls test was used to compare (1) the frequencies of the ideation, synthesis and assessment phases of the design cycle were compared using and (2) the distribution of the number of 
$\mathrm{W}$-cycles completed across the four quarters of the design project. In both analyses, data were tested for normality using a Kolmogorov-Smirnov test, and differences were considered significant at $p<0.05$.

\section{Questionnaire}

Forty-six questionnaires were used for the analysis (two students did not submit their questionnaires). Completed questionnaires were transcribed verbatim and analyzed using qualitative research software (NVivo 9, QSR International). The constant comparative method (Corbin and Strauss 2008) was used to examine similar emerging themes in the transcripts of the participants. Initially, open coding was used by two members of the research team individually to code all transcripts. This involved assigning a word or a phrase to capture the meaning of lines or phrases in the transcripts. These open codes were reviewed to discuss commonalities and resolve differences of opinion by refining codes until consensus was achieved. Transcripts were then micro-analyzed line by line, and open codes were applied to data segments that summarized content. Discrepancies in this phase of the coding were resolved by discussions amongst the research team. Axial coding was then used to group the assigned open codes to each of the eight predicted outcomes of the W-model presented in Table 2.

\section{Results}

\section{Student-maintained logbooks were a reliable record of the design process}

There was 'moderate agreement' $(\kappa=0.45 \pm 0.04)$ between third-party observations of student design procedures and logbook records (Landis and Koch 1977). A representative dataset demonstrating the overlap between logbook and observer datasets is provided in Fig. 5a. These results demonstrate the reliability of the student-maintained logbooks in recording the design process.

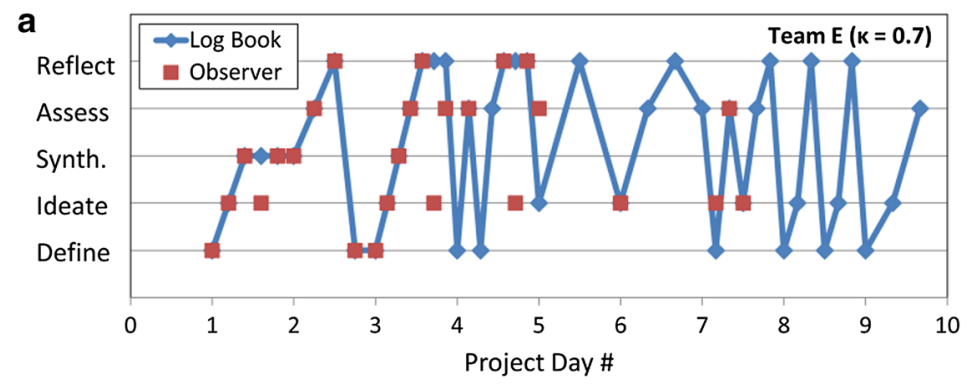

b

\begin{tabular}{rcccccccccc}
\hline Team Code: & A & B & C & D & E & F & G & H & I & Avg \pm Std Err \\
\hline \# of W-Cycles & 5 & 7 & 9 & 8 & 8 & 7 & 5 & 7 & 6 & $6.89 \pm 0.45$ \\
\# times changed scope & 3 & 5 & 4 & 5 & 5 & 4 & 4 & 6 & 3 & $4.33 \pm 0.33$ \\
\hline
\end{tabular}

Fig. 5 Logbook analysis. a Design team logbook records and observer datasets show moderate agreement (representative dataset). b Total number of design cycles and times the project changed scope over the course of the design project 

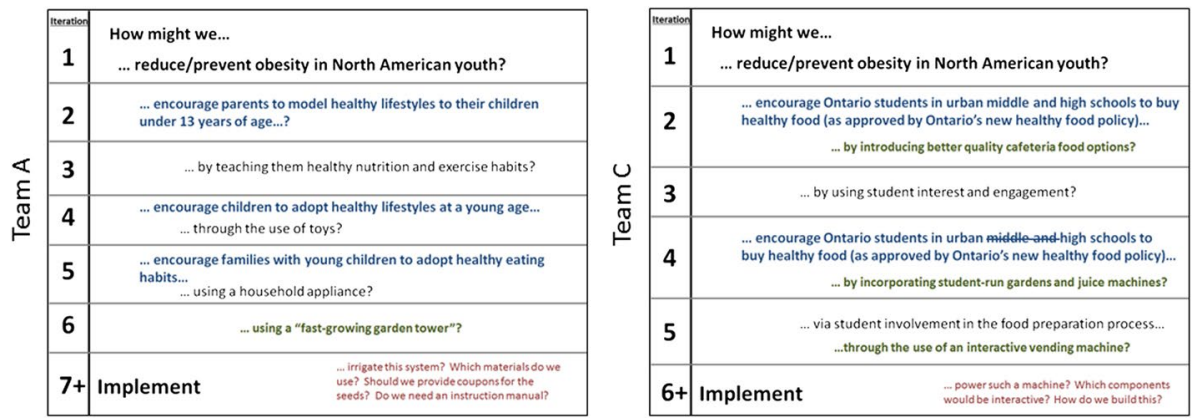

Fig. 6 Examples drawn from two design teams illustrating how the design problem changed scope at the beginning of each W-cycle over the course of the design project

\section{Outcome 1: Students used the W-model to continually refine their understanding of the problem from project onset to project end}

The problem statement recorded in student logbooks during the "define" stage significantly changed across subsequent design cycles, as illustrated in Fig. 6. Logbook analysis demonstrated that teams changed scope an average of $4.3 \pm 0.3$ times (Fig. 6b). Questionnaire responses also revealed that students found the $\mathrm{W}$-model useful for refining their understanding and scope of the problem. "At first, the model was incredibly useful for narrowing down a problem with that great a scope. It gave us a way to tackle the massive problem at hand." "In some situations, especially ones with a very broad focus, it was very intuitive to use the W-model, because we had a fairly good idea of where we would end up after a cycle-with a narrower focus."

\section{Outcome 2: Students generated many ideas and did not become fixated on their first one}

During the ideate phase of each design cycle, students recorded an average of 36 ideas in their logbooks. Questionnaire responses revealed that students exhibited the beginner designer tendencies to generate few ideas or to become fixated on an early idea. "We wanted to get to the solutions fast." "Being constantly reminded to use [the W-model] was, although irritating at first (because we just wanted to GET TO THE SOLUTION!), actually incredibly helpful in the long run." However, students reported that the W-model was able to successfully divert design teams away from this behavior, towards that of the informed designer. "With the abstract problem, some teammates wanted to jump forward to one single solution that they became personally attached to. However, we were able to convince them to stay on track. The W-model really helps at this level." "The way in which [the $\mathrm{W}$-model] diverts thinking away from trying to devise an immediately effective solution and more towards a decrease in abstraction is, I think, an essential part of what expert designers do." Furthermore, students found that the W-model helped to generate "good" and "unique" ideas from the "wild" ideas that arise in a brainstorm: "It really forces you to ... consider where the crazy solutions come from... and then come up with a totally unique solution that would have never come to mind any other way." "The ideation phase encouraged wild ideas, and those wild ideas helped us generate themes/important aspects that we may not have found if we only shared 'good' ideas." 


\section{Outcome 3: Students used higher order criteria to critically assess ideas}

All 9 design teams demonstrated evidence of using the "feasibility, validity and desirability" criteria to evaluate their design ideas in their logbooks. Students reported frustration and a lack of progress when they engaged in the assessment phase without applying these higher order criteria. "So our cycle is basically ideate, synthesize, argue, ideate, etc. Argument occurs because we couldn't draw the line between objective assessment and subjective assessment." "Although some group members are more strongly attached than others, we all had biases, so assessment was impossible because different ideologies and ethical values ignited arguments that sidetracked the group." Questionnaire responses revealed that though students may not have used these criteria without the prescription of the W-model, they understood the value of doing so in retrospect. "Though sometimes we felt the assessment phase was unnecessary, we went through each cycle thoroughly. Afterwards, we realized it did help us to come to a substantial solution." "I think if we didn't have the model, it would have been much more difficult to come up with a solution that would be feasible, desirable, and viable without wasting a lot more time criticizing everyone's opinions."

\section{Outcome 4: Students built prototypes and conducted research to learn more about the problem}

All 9 design teams reported building prototypes and conducting research throughout the design process in their logbooks. Questionnaire responses demonstrated that students understood the value of using these tools to advance through the design process. "Some example decisions: 'what size of pots?' 'what material?' 'how tall?' 'what colours?' We found these were best resolved through quick research, prototyping and discussion."

\section{Outcome 5: Students understood where they were in the overall design process and modified design strategies according to deadlines for deliverables}

Questionnaire responses revealed that students understood felt comfortable with where they were in the overall design process as a result of the W-model. "I felt that [the model] guided us through the design project, which was reassuring." "It is a clearer visual representation of where you are, where you've been, and where you are going; it helps you not to get lost in such a massive problem." "It really helped structure my first design experience. We always knew what to do next and what lay ahead." "This was my first experience with the design and it felt like it went so well and smoothly because we were given this framework and it was very easy to pick-up once going through the complete cycle once with our own designs."

Furthermore, logbook analysis revealed that students were able to modify their design strategies based on where they were in the overall process. Figure 7 illustrates the breakdown of "ideation", "synthesis" and "assessment" activities reported in team logbooks across each quarter of the design project. Figure 7 a demonstrates that students did not blindly repeat the same design pattern throughout the project, but modified how often they used each activity during each cycle. The total amount of ideation did not change significantly across the project course. However, synthesis activities were performed significantly 


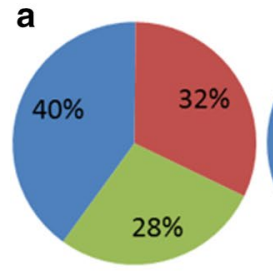

Q1

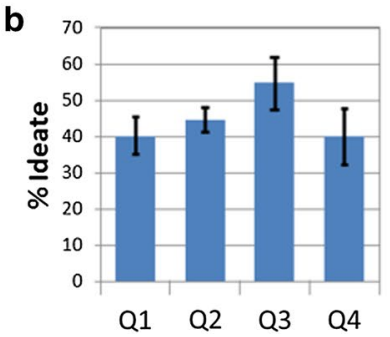

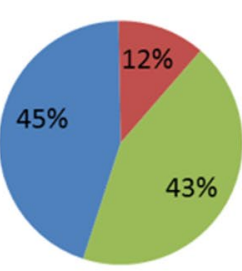

Q2

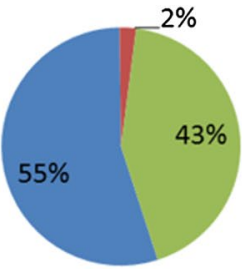

Q3

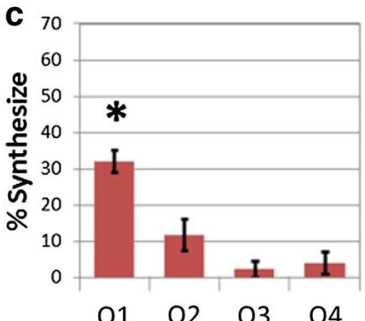

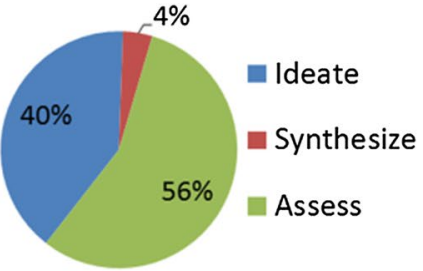

Q4

d 70

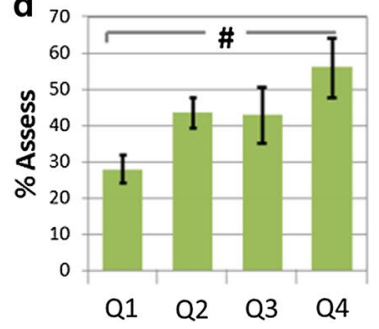

Fig. 7 Distribution of 'ideate', 'synthesize' and 'assess' phases across the four quarters (Q1-Q4) of the design project. a Student engagement with these three design phases varied across the four quarters. b Frequency of ideate phases did not vary across the quarters, while $\mathbf{c}$ synthesis phases occurred more frequently in the first quarter, and $\mathbf{d}$ assessment phases occurred more frequently in the last quarter. ${ }^{*} p<0.05$ compared to all other datapoints; ${ }^{\#} p<0.05$ compared to indicated datapoints

more frequently in early design cycles and assessment activities were performed significantly more frequently in later design cycles (Fig. 7b).

\section{Outcome 6: Students engaged in multiple design cycles}

Logbook analysis revealed that the design teams attempted an average total of $6.9 \pm 0.5$ design cycles over $30 \mathrm{~h}$ of project time (Fig. 5b). However, these design cycles were not distributed uniformly throughout the course of the project. The normalized distribution of W-cycles initiated by each team, as a function of project quarter (Fig. 8) illustrate that students used the model significantly more frequently during the initial two quarters of the project, as compared to the last two quarters. Questionnaire responses confirm these

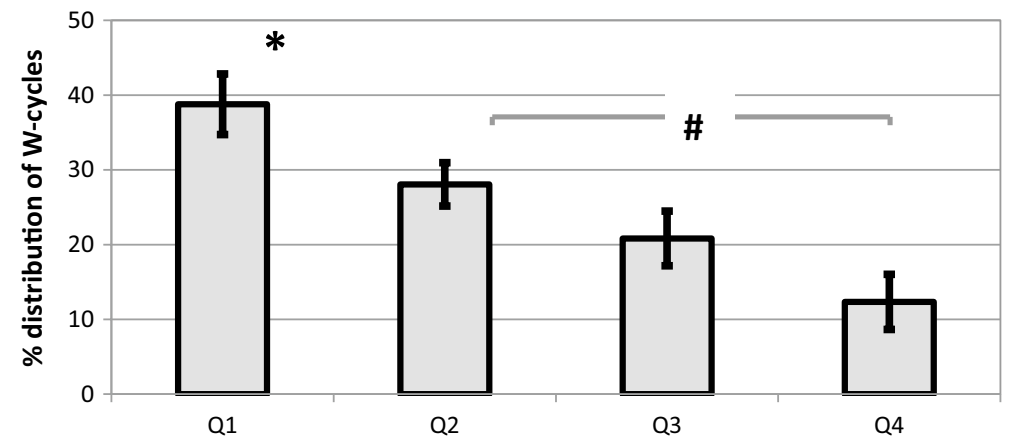

Fig. 8 Normalized distribution of the percentage of W-cycles completed across each quarter of the design project. ${ }^{*} p<0.05$ compared to all other datapoints; ${ }^{\#} p<0.05$ compared to indicated datapoints 
quantitative results, and describe how formal design cycles are less helpful when the project solutions become more concrete. "My group followed a few W-cycles in the later part of the design project, only to find that it takes more time, and does not lead to anything more insightful than what could have been found just by thinking about it." "Once we chose our solution we found that the model was not efficient for the numerous small design choices we had to make, we could have used it but each of the $100+$ small decisions would have taken around fifteen minutes [each]."

\section{Outcome 7: Students allowed themselves to backtrack when they discovered a flaw in their design}

Examination of the evolution of the problem presented in the "define" stage of team logbooks demonstrated that students were willing to backtrack and make their problem more abstract (Fig. 6). Questionnaire responses revealed that students tended toward the beginner designer tendency of not revising a problem based on a previous design cycle: "A lot of the time, we didn't want to go 'up' the cycle and turn... more abstract." "It was hard to decide whether we were going to go with one theme and start a new cycle, or to think it through some more, because we didn't want to get to a point [where we needed] to start over". However, in spite of negative feelings that students had towards this part of the process, questionnaire responses demonstrated that students did not avoid it: "After reflecting on what was learnt, the entire problem was changed, as opposed to just being built upon."

\section{Overall impressions of the W-model indicated a steep learning curve, but positive outcomes}

The participants' responses to their experience using the W-model to solve a wicked problem were varied. Several students described the framework as 'structured', 'helpful', 'useful' and 'concrete'; others reported that it was also 'difficult to get used to', 'tedious' and 'restrictive'. Participants generally indicated that the initial steep learning curve was offset by the benefits of using the W-model to guide their design process: "Overall, although the model may be a pain to get used to, once you do, it's an amazing tool and strategy that can be used to find valid solutions to some of the biggest problems out there - it really forces you to think outside the box, consider where the crazy solutions come from, and if there's any real sense to them, and then come up with a totally unique solution that would have never come to mind any other way." "Although during the process, I felt that the W-cycle was hard to use and was pointless, now that I finished the project I think that the model helped us a lot." "I found that the model, once understood, was a very helpful tool in making the design process easier for us novice designers and without it I think the quality of projects design [sic] would decrease because of that lack of a structured framework to work with."

\section{Discussion}

The current study demonstrates that pre-college students who use the $\mathrm{W}$-model as a framework for designing a solution to a wicked problem exhibit behaviours associated with informed designers. Through multiple, rapid iterations through $\mathrm{W}$-cycles, student refine their understanding of the problem as they explore potential solutions, do not become 
fixated on a single idea, use higher order criteria to evaluate potential solutions, build prototypes and conduct research throughout the project, understand where they are in the overall design process and allow themselves to backtrack when flaws are discovered in their current design trajectory. These behaviours allow them to confidently and effectively engage with complex problems.

\section{Best practices in using the $\mathrm{W}$-model}

We emphasize several best instructional practices for the W-model in order to ensure that students acquire design competency in a timely manner. (1) It is important for students to continually co-construct their understanding of the problem and its solutions when dealing with wicked problems (Beckman and Barry 2012; Maher and Tang 2003). We encourage students to have concrete representations of their current understanding of the problem by writing down a refined problem definition at the beginning of every $\mathrm{W}$ cycle. (2) During the ideate phase, we encourage students to write each idea onto a separate piece of paper or sticky note. In the subsequent synthesis phase, we ask students to actively arrange and rearrange the papers to cluster ideas under different themes, and to ensure that every idea belongs to at least one group. This forces students to perform a level of abstraction in order to ensure that the best qualities of every ideated solution are extracted, which overcomes some known limitations of group brainstorming (Byron 2012; Kohn and Smith 2011; Nemeth et al. 2003). (3) We emphasize the importance of rapid iteration (Adams et al. 2003; Jr and Gyeszly 1991; Lawson and Dorst 2009). To support this, we guide the first several W-cycles in a classroom exercise. With the design groups working in the same space, instructors structure the time, announcing when they expect design groups to be transitioning from one phase of the $\mathrm{W}$ to the next, and reminding the groups what occurs in the next phase. We aim to encourage each design group to complete $2-3 \mathrm{~W}$-cycles within the first $3 \mathrm{~h}$ of the project. (4) It is important to give students permission to revisit their assumptions when faced with evidence that their assumptions have become problematic (Perkins 1995, pp. 218-220). In order to encourage this behavior, which many students perceive as a step backwards, students are asked to present the different trajectories they have explored during each deliverable of the project. This allows students to feel that their work has not been wasted, and that exploring different design trajectories is an expected part of the design process.

\section{Limitations}

Results of the study reveal two limitations of the W-model. First, while student design behavior evolved mostly as predicted, the distribution of design cycles throughout the project was unexpected. Students tended to use the W-model more frequently in the beginning in the initial stages of the project, when the teams' current understanding of the problem was still too abstract to apply conventional design methodologies (Fig. 8). As the problem became more concrete and better defined, students perceive the W-model to be less useful. Furthermore the design activities students engaged with in each cycle varied across the course of the project. While ideation remained relatively constant throughout the design process, synthesis decreased and assessment increased significantly over time (Fig. 7). This shift might be attributed to the changing goal of the cycle and the nature of the ideated solutions, as the design process progresses. Earlier on, the solutions are broader and more amenable to clustering in the synthesis phase; conversely, later solutions are more practical 
and specific and more amenable to prototyping and direct assessment. These results suggest that the $\mathrm{W}$-model is most useful when applied to complex problems. If students begin with a well-defined problem, such as a traditional design brief, the benefits of the W-model are more limited. Second, the benefits of the W-model have only been demonstrated on novice pre-college designers, who have minimal disciplinary expertise, and thus are mostly limited to their personal knowledge in solving problems. The utility of the $\mathrm{W}$-model in guiding novice designers who have a depth of technical knowledge, and in formal educational settings, must be determined in future studies.

\section{Conclusion}

Current pre-college engineering design pedagogies do not adequately teach behaviors that informed designers use to solve wicked problems. The $\mathrm{W}$-model is a novel design framework that guides pre-college students towards behaviors that effectively address wicked problems. Quantitative and qualitative evidence converge to demonstrate that using the $\mathrm{W}$-model enabled design teams to: continually refine their understanding of the problem; practice idea fluency and not become fixated on one idea; use higher order criteria to assess ideas; perform investigations to learn about the problem; understand where they are in the overall design process; engage in multiple design cycles and backtrack when they discover a flaw in their design. These results provide evidence for the effectiveness of using prescriptive frameworks that encourage rapid cycling between understanding problems and developing solutions to teach novice designers to solve complex problems. Such pedagogical frameworks should be adopted into engineering education practice in order to train future engineers to address complex, real-world challenges.

Acknowledgements We would like to thank Ed Jernigan and Paul McKone for their helpful discussion of these ideas. We would also like to thank Ethan Jernigan, Eric Kennedy, Jenna Vikse, Marie Leung, Michelle Metzger and Ryan Voisin for their help with data collection.

\section{References}

Adams, R. S., \& Atman, C. J. (2000). Characterizing engineering student design processes: An illustration of iteration. Retrieved from internal-pdf: https://peer.asee.org/characterizing-engineering-student-desig n-processes-an-illustration-of-iteration.pdf. Accessed 7 Aug 2019.

Adams, R. S., Turns, J., \& Atman, C. J. (2003). Educating effective engineering designers: The role of reflective practice. Design Studies, 24(3), 275-294. https://doi.org/10.1016/S0142-694X(02)00056-X.

Andrews, D. H., \& Goodson, L. A. (1980). A comparative analysis of models of instructional design. Journal of Instructional Development, 3(4), 2-16. https://doi.org/10.1007/BF02904348.

Archer, B. (1979). Design as a discipline. Design Studies, 1(1), 17-20. https://doi.org/10.1016/0142694X(79)90023-1.

Beckman, S. L., \& Barry, M. (2012). Teaching student problem framing skills with a storytelling metaphor. International Journal of Engineering Education, 28(2), 364-373.

Bereiter, C., \& Scardamalia, M. (1993). Surpassing ourselves: An inquiry into the nature and implications of expertise. Chicago: Open Court.

Brown, T. (2009). Change by design: How design thinking transforms organizations and inspires innovation. New York: HarperBusiness.

Buchanan, R. (1992). Wicked problems in design thinking. Design Issues, 8(2), 5-21. https://doi. org/10.2307/1511637. 
Byron, K. (2012). Creative reflections on brainstorming. London Review of Education, 10(2), 201-213. https://doi.org/10.1080/14748460.2012.691284.

Carson, L., Jernigan, E., McKone, P., Roe, P., \& Schmitke, C. (2008). Designer boot camp: An immersion in design practice as high school enrichment. Design Principles and Practices: An International Journal, 2(3), 29-35.

Cho, K.-L., \& Jonassen, D. H. (2002). The effects of argumentation scaffolds on argumentation and problem solving. Educational Technology Research and Development, 50(3), 5-22. https://doi. org/10.1007/BF02505022.

Christiaans, H., \& Dorst, C. (1992). Cognitive models in industrial design engineering: A protocol study. In D. L. Taylor \& D. A. Stauffer (Eds.), Design theory and methodology. New York: American Society of Mechanical Engineers.

Cohen, J. (1960). A coefficient of agreement for nominal scales. Educational and Psychological Measurement, 20, 37-46.

Conklin, E. J., \& Weil, W. (2007). Wicked problems: Naming the pain in organizations. White Paper, 13. www.accelinnova.com/docs/wickedproblems.pdf. Accessed 19 Jan 2016.

Corbin, J. M., \& Strauss, A. L. (2008). Basics of qualitative research: Techniques and procedures for developing grounded theory. Los Angeles: SAGE.

Creswell, J. W., Clark, V. L. P., Creswell, J. W., \& Clark, V. L. P. (2010). Designing and conducting mixed methods research (2nd ed.). Los Angeles: Sage Publications.

Crismond, D. (2001). Learning and using science ideas when doing investigate-and-redesign tasks: A study of naive, novice, and expert designers doing constrained and scaffolded design work. Journal of Research in Science Teaching, 38(7), 791-820. https://doi.org/10.1002/tea.1032.

Crismond, D., Camp, P. J., Ryan, M., \& Kolodner, J. L. (2001). Design rules of thumb_Connecting science and design. Presented at the annual conference of the American Educational Research Association, Seattle, Washington, US.

Crismond, D. P., \& Adams, R. S. (2012). The informed design teaching and learning matrix. Journal of Engineering Education, 101(4), 738-797. https://doi.org/10.1002/j.2168-9830.2012.tb01127.x.

Cross, N. (2008). Engineering design methods: Strategies for product design. Hoboken, NJ: Wiley.

Daly, S. R., Adams, R. S., \& Bodner, G. M. (2012). What does it mean to design? A qualitative investigation of design professionals' experiences. Journal of Engineering Education, 101(2), 187-219. https://doi.org/10.1002/j.2168-9830.2012.tb00048.x.

Design Squad Nation. (n.d.). The design process in action. http://pbskids.org/designsquad/parentsedu cators/workshop/process.html. Accessed 7 Aug 2019.

Dorst, K., \& Cross, N. (2001). Creativity in the design process: Co-evolution of problem-solution. Design Studies, 22(5), 425-437.

Dreyfus, H., \& Dreyfus, S. (2005). Expertise in real world contexts. Organization Studies, 26(5), 779-792.

Dreyfus, H. L., Dreyfus, S. E., \& Athanasiou, T. (1986). Mind over machine: The power of human intuition and expertise in the era of the computer. New York: Free Press.

Dubberly, H. (2005). How do you design? A compendium of models. San Francisco: Dubberly Design Office.

Dunne, D., \& Martin, R. (2006). Design thinking and how it will change management education: An interview and discussion. Academy of Management Learning and Education, 5(4), 512-523.

Dym, C. L., Agogino, A. M., Eris, O., Frey, D. D., \& Leifer, L. J. (2005). Engineering design thinking, teaching, and learning. Journal of Engineering Education, 94(1), 103-121.

French, S. (1992). Simulation exercises in disability awareness training: A critique. Disability, Handicap \& Society, 7(3), 257-266. https://doi.org/10.1080/02674649266780261.

Goldman, E. (2006). Search engine bias and the demise of search engine utopianism (SSRN Scholarly Paper No. ID 893892). Retrieved from Social Science Research Network website: http://paper s.ssrn.com/abstract=893892. Accessed 7 Aug 2019.

Guindon, R. (1990). Designing the design process: Exploiting opportunistic thoughts. Human-Computer Interaction, 5, 305-344.

Hatchuel, A., Le Masson, P., \& Weil, B. (2011). Teaching innovative design reasoning: How conceptknowledge theory can help overcome fixation effects. Artificial Intelligence for Engineering Design, Analysis and Manufacturing, 25, 72-92.

Hatchuel, A., \& Weil, B. (2003). A new approach of innovative design: An introduction to C-K theory. In International conference on engineering design ICED 03 Stockholm, August 19-21, 2003.

Hynes, M. M. (2012). Middle-school teachers' understanding and teaching of the engineering design process: A look at subject matter and pedagogical content knowledge. International Journal of Technology and Design Education, 22(3), 345-360. https://doi.org/10.1007/s10798-010-9142-4. 
International Technology Education Association. (2002). Standards for technological literacy: Content for the study of technology (2nd ed.). Reston: International Technology Education Association.

Jonassen, D., Strobel, J., \& Lee, C. B. (2006). Everyday problem solving in engineering: Lessons for engineering educators. Journal of Engineering Education, 95(2), 139-151. https://doi. org/10.1002/j.2168-9830.2006.tb00885.x.

Jonassen, D. H. (2000). Toward a design theory of problem solving. Educational Technology Research and Development, 48(4), 63-85. https://doi.org/10.1007/BF02300500.

Jr, C. W. E., \& Gyeszly, S. W. (1991). Protocol analysis of the engineering systems design process. Research in Engineering Design, 3(1), 15-22. https://doi.org/10.1007/BF01580065.

K12 Lab Network. (n.d.). Retrieved October 15, 2013, from K12 Lab network website: http://www.k12la b.org.

Katehi, L., Pearson, G., \& Feder, M. (Eds.). (2009). Engineering in K-12 education: Understanding the status and improving the prospects. http://www.nap.edu/catalog.php?record_id=12635. Accessed 7 Aug 2019.

King, J. B. (1993). Learning to solve the right problems: The case of nuclear power in America. Journal of Business Ethics, 12(2), 105-116.

Kohn, N. W., \& Smith, S. M. (2011). Collaborative fixation: Effects of others' ideas on brainstorming. Applied Cognitive Psychology, 25(3), 359-371. https://doi.org/10.1002/acp.1699.

Lande, M., \& Leifer, L. (2010). Incubating engineers and hatching design thinkers: Mechanical engineering students learning design with ambidextrous ways of thinking. In Proceedings of the Annual American Society for Engineering Education conference. Presented at the Louisville, KY.

Landis, J. R., \& Koch, G. G. (1977). The measurement of observer agreement for categorical data. Biometrics, 33(1), 159-174. https://doi.org/10.2307/2529310.

Lawson, B., \& Dorst, K. (2009). Design expertise. Burlington, MA: Architectural Press.

Lucky, R. W. (2009). Wicked problems [reflections]. IEEE Spectrum, 46(7), 27. https://doi.org/10.1109/ MSPEC.2009.5109448.

Maher, M. L., \& Tang, H. H. (2003). Co-evolution as a computational and cognitive model of design. Research in Engineering Design, 14(1), 47-63.

Mangold, J., \& Robinson, S. (2013, June 23). The engineering design process as a problem solving and learning tool in K-12 classrooms. Presented at the 120th ASEE annual conference \& exposition, Atlanta, Georgia.

Mcadoo, M. (1998). Companies steer new K-12 courses [education]. IEEE Spectrum, 35(4), 27-33. https:// doi.org/10.1109/6.666957.

Morgan, D. L. (2007). Paradigms lost and pragmatism regained: Methodological implications of combining qualitative and quantitative methods. Journal of Mixed Methods Research, 1(1), 48-76.

Morse, J. M. (1991). Approaches to qualitative-quantitative methodological triangulation. Nursing Research, 40, 120-123.

National Research Council. (2005). National science education standards. Washington, DC: National Academy Press.

Nemeth, C., Personnaz, M., Personnaz, B., \& Goncalo, J. (2003). The liberating role of conflict in group creativity: A cross cultural study. http://papers.ssrn.com/sol3/papers.cfm?abstract_id=440663. Accessed 7 Aug 2019.

Osborn, A. F. (1963). Applied imagination: Principles and procedures of creative problem-solving. New York: Scribner.

Perkins, D. N. (1995). Outsmarting IQ: The emerging science of learnable intelligence. New York: Free Press.

Project Lead The Way. (n.d.). www.pltw.org.

Rittell, H. W. J., \& Webber, M. M. (1972). Dilemmas in a general theory of planning. Berkeley: University of California at Berkeley.

Schön, D. A. (1983). The reflective practitioner: How professionals think in action. New york: Basic Books.

Schön, D. A. (1988). Designing: Rules, types, and worlds. Design Studies, 9, 181-190.

Schraw, G., Dunkle, M. E., \& Bendixen, L. D. (1995). Cognitive processes in well-defined and ill-defined problem solving. Applied Cognitive Psychology, 9(6), 523-538. https://doi.org/10.1002/acp.23500 90605.

Shin, N., Jonassen, D. H., \& McGee, S. (2003). Predictors of well-structured and ill-structured problem solving in an astronomy simulation. Journal of Research in Science Teaching, 40(1), 6-33. https://doi. org/10.1002/tea.10058.

Simon, H. A. (1969). Science of the artificial. Cambridge: MIT Press.

Sternberg, R. J. (1998). Metacognition, abilities, and developing expertise: What makes an expert student? Instructional Science, 26(1-2), 127-140. https://doi.org/10.1023/A:1003096215103. 
Tai, R. H., Liu, C. Q., Maltese, A. V., \& Fan, X. (2006). Planning early for careers in science. Science, 312(5777), 1143-1144. https://doi.org/10.1126/science.1128690.

Wodehouse, A. J., Grierson, H. J., Breslin, C., Eris, O., Ion, W. J., Leifer, L. J., et al. (2010). A framework for design engineering education in a global context. Artificial Intelligence for Engineering Design, Analysis and Manufacturing, 24(3), 367-378.

Publisher's Note Springer Nature remains neutral with regard to jurisdictional claims in published maps and institutional affiliations. 